were subjected to a hierarchical clustering analysis. The DEGs (group S vs. $\mathrm{C}$ and post vs. pre) were also investigated with weighted gene co-expression network analysis (WGCNA) and GO analysis. Meanwhile, the total eigengene expressions of the important modules identified by WGCNA in each cases were also calculated.

Results: Surprisingly, 8 out of the top 10 enriched GO terms in the up-regulated genes were relevant to leukocyte activation such as 'neutrophil migration" by the analysis of DEGs (post vs. pre) in group C. The cluster analysis of 'pre' genes confirmed that the patterns of gene expression between group $S$ and $C$ was different. WGCNA analysis of DEGs (group $S$ vs. $C$ ) revealed that genes related to acute inflammation such as 'leukocyte mediated immunity' were activated in group S. Interestingly, it was not correlated with disease activity score (DAS) of RA. By the analysis of DEGs (post vs. pre) of upregulated genes, we found that the total eigengene expressions of the module enriched with genes related to 'cell adhesion' or 'leukocyte migration' were significantly increased in all cases of group $\mathrm{S}$.

Conclusion: This is the first evidence that the genes associated with neutrophil migration is significantly activated after TCZ-Tx. It is noteworthy that the gene activation was observed in cases without any side effects. The decreased neutrophil counts in peripheral blood have been known after initiation of TCZ-Tx, which did not affect the rate of serious infections. Recently, It was reported that TCZ affects neutrophil trafficking to the bone marrow ${ }^{1}$. Our findings will provide a rationale for its cause. On the other hand, we experienced several RA cases with development of various skin rashes associated with neutrophil activation after TCZ-Tx. However, majority of patients do not develop the side effect, even though genes related to 'neutrophil migration' are activated. In group S, our findings indicate that the genes related to 'leukocyte mediated immunity' was already activated at the initiation of treatment without correlating to DAS of RA, furthermore, the gene upregulation related to 'leukocyte migration' was more prominent after TCZ-Tx. Although it is difficult to predict the patients developing skin rashes before TCZ-Tx, we do not recommend to use TCZ for the patients with neutrophilic dermatosis which is often associated with RA.

References: :

[1] Lok LSC et al., Eur J Clin Invest. 47(10):736-745 (2017).

Disclosure of Interests: : Moe Sakamoto: None declared, Akemi Senoh: None declared, Yoshiharu Sato: None declared, Hiroshi lijima: None declared, Mari Yamaguchi: None declared, Toshie Higuchi: None declared, Yoshinobu Koyama Grant/research support from: Eli-Lilly and Mochida., Speakers bureau: BMS, Ayumi, Chugai, Ono, Mitsubishi Tanabe, Abbvie and Eisai.

DOI: 10.1136/annrheumdis-2020-eular.3900

\section{SAT0120 UNITED STATES RHEUMATOLOGY PRACTICE-BASED REAL-WORLD EVIDENCE OF INFUSION REACTIONS IN RHEUMATOID ARTHRITIS PATIENTS TREATED WITH INTRAVENOUS GOLIMUMAB OR INFLIXIMAB: IMPACT OF PRIOR BIOLOGIC EXPOSURE AND METHOTREXATE UTILIZATION}

S. Schwartzman ${ }^{1}$, A. Broadwell ${ }^{2}$, A. Kivitz ${ }^{3}$, S. Black ${ }^{4}$, S. Xu ${ }^{5}$, W. Langholff ${ }^{5}$, S. Kafka ${ }^{4}{ }^{7}$ Weill Cornell Medical College, NY, United States of America; ${ }^{2}$ Rheumatology and Osteoporosis Specialists, LA, United States of America; ${ }^{3}$ Altoona Center for Clinical Research, PA, United States of America; ${ }^{4}$ Janssen Scientific Affairs, LLC, PA, United States of America; 5 Janssen Research \& Development, LLC, PA, United States of America

Background: AWARE (Comparative and Pragmatic Study of Golimumab IV Versus Infliximab in Rheumatoid Arthritis) is an ongoing Phase 4 comparator study designed to provide a real-world assessment of intravenous golimumab (GLM) and intravenous infliximab (IFX) in patients (pts) with rheumatoid arthritis (RA). The study recently reached its primary endpoint (comparison of overall incidence of infusion reactions in GLM- vs IFX-treated pts after 52 weeks) with the last patient reaching 52 weeks of treatment or discontinuation from the study. AWARE also records prior use of biologic medications and concomitant use of methotrexate (MTX).

Objectives: To assess the incidence of infusion reactions among GLM and IFX pts reported at baseline by examining the influence of prior biologic exposure or concurrent use of MTX.

Methods: AWARE is a prospective, noninterventional, observational, multicenter, 3 -year study conducted in the US. RA patients ( 1,270 adults) were enrolled at the time of initiating treatment with GLM or IFX. All treatment decisions were made at the discretion of the treating rheumatologist. An infusion reaction was any adverse event that occurred during an infusion or within 1 hour after the infusion of either GLM or IFX. Imputations were not performed on these AWARE data. Data shown are mean \pm standard deviation.

Results: Demographics are shown in Table 1 and the incidence of infusion reactions in different AWARE cohorts is shown in Table 2. GLM and IFX pts were comparable in sex and utilization of MTX at baseline. Both age and disease duration of GLM pts was greater than IFX pts by $\sim 2$ years. There was a higher proportion of bionaïve pts in IFX-treated group compared to GLM-treated group. Overall, infusion reactions occurred more frequently among IFX-treated pts compared to GLM-treated pts. The difference in infusion reaction rates between IFX- and GLM-treated pts was also evident among subgroups of bionaïve vs non-bionaïve pts, and among MTX non-users vs MTX users (characteristics reported at baseline). GLM pts did not report any serious or severe infusion reactions. These were reported rarely (3/585 pts) in IFX-treated pts. Among GLM and IFX pts with an infusion reaction, $55.6 \%$ of GLM and $77.1 \%$ of IFX pts had at least one medication for infusion reaction. Infusion reactions accounted for $9.7 \%$ and $35.1 \%$ of discontinuations due to adverse events in GLM and IFX pts, respectively.

Table 1. Baseline Characteristics in the AWARE Study

\begin{tabular}{lcc}
\hline & GLM $(\mathbf{n}=\mathbf{6 8 5})$ & IFX $(\mathbf{n}=\mathbf{5 8 5})$ \\
\hline Age (years) & $60.9 \pm 13.43$ & $58.0 \pm 12.85$ \\
Sex (\% female) & $85.0 \%$ & $79.5 \%$ \\
Disease Duration (years) & $9.16 \pm 9.975$ & $7.20 \pm 9.716$ \\
Bionaïve (\%) & $33.0 \%$ & $48.6 \%$ \\
MTX plus (\%) & $75.4 \%$ & $75.1 \%$ \\
\hline
\end{tabular}

MTX=methotrexate

Table 2. Infusion Reactions in AWARE in Subsets of Patients \pm Prior Biologic Use or \pm Concurrent MTX

\begin{tabular}{|c|c|c|c|c|c|c|c|c|}
\hline & \multicolumn{2}{|c|}{ GLM $(n=685)$} & \multicolumn{2}{|c|}{ IFX $(n=585)$} & \multicolumn{2}{|c|}{ GLM $(n=685)$} & \multicolumn{2}{|c|}{ IFX $(n=585)$} \\
\hline & Bionaïve & $\begin{array}{c}\text { Non- } \\
\text { Bionaïve }\end{array}$ & Bionaïve & $\begin{array}{c}\text { Non- } \\
\text { Bionaïve }\end{array}$ & $\begin{array}{c}\text { No MTX } \\
\text { Use }\end{array}$ & $\begin{array}{l}\text { MTX } \\
\text { Use }\end{array}$ & $\begin{array}{c}\text { No MTX } \\
\text { Use }\end{array}$ & $\begin{array}{l}\text { MTX } \\
\text { Use }\end{array}$ \\
\hline $\begin{array}{l}\text { Infusion } \\
\text { Reactions }\end{array}$ & $\begin{array}{c}6 / 242 \\
(2.5 \%)\end{array}$ & $\begin{array}{l}21 / 443 \\
(4.7 \%)\end{array}$ & $\begin{array}{c}36 / 251 \\
(14.3 \%)\end{array}$ & $\begin{array}{c}47 / 334 \\
(14.1 \%)\end{array}$ & $\begin{array}{l}15 / 265 \\
(5.7 \%)\end{array}$ & $\begin{array}{l}12 / 420 \\
(2.9 \%)\end{array}$ & $\begin{array}{c}44 / 229 \\
(19.2 \%)\end{array}$ & $\begin{array}{l}39 / 356 \\
(11.0 \%)\end{array}$ \\
\hline $\begin{array}{l}\text { Medication } \\
\text { for Infusion } \\
\text { Reactions }\end{array}$ & $33.3 \%$ & $59.1 \%$ & $78.9 \%$ & $73.6 \%$ & $50 . \%$ & $58.3 \%$ & $73.6 \%$ & $77.6 \%$ \\
\hline
\end{tabular}

MTX=methotrexate

Conclusion: Whether bionaïve, non-bionaïve, MTX non-user or MTX user at baseline, the incidence of infusion reactions was notably lower among GLM- vs IFX-treated pts. Serious and/or severe infusion reactions did not occur among GLM pts and were rare among IFX pts. IFX was more commonly administered mediation for an infusion reaction compared to GLM. Infusion reactions accounted for almost four times the number of discontinuations related to adverse events in IFX pts compared to GLM pts. Disclosure of Interests: : Sergio Schwartzman Grant/research support from: Jans sen Research \& Development, LLC, Consultant of: AbbVie, Crescendo Bioscience, Dermtech, Eli Lilly and Company, Gilead Sciences, Janssen Pharmaceutica, Myriad Genetics, Novartis, Regeneron, Samsung, Sanofi, UCB, Speakers bureau: AbbVie, Eli Lilly and Company, Genentech, Janssen Pharmaceutica, Novartis, Pfizer, Regeneron, Sanofi, UCB, Aaron Broadwell Grant/research support from: Janssen Research \& Development, LLC, Janssen, Eli Lilly, Consultant of: AbbVie, Amgen, AstraZeneca, Celgene, Eli Lilly, Janssen, Novartis, Pfizer, Sandoz, Speakers bureau:AbbVie, Amgen, Celgene, GSK, Horizon, Janssen, Mallinckrodt, Novartis, Pfizer, Radius, Sanofi-Regeneron, UCB, Alan Kivitz Shareholder of: AbbVie, Amgen, Gilead, GSK, Pfizer Inc, Sanofi, Consultant of: AbbVie, Boehringer Ingelheim,,Flexion, Genzyme, Gilead, Janssen, Novartis, Pfizer Inc, Regeneron, Sanofi, SUN Pharma Advanced Research, UCB, Paid instructor for: Celgene, Genzyme, Horizon, Merck, Novartis, Pfizer, Regeneron, Sanofi, Speakers bureau: AbbVie, Celgene, Flexion, Genzyme, Horizon, Merck, Novar tis, Pfizer Inc, Regeneron, Sanofi, Shawn Black Employee of: Janssen Research \& Development, LLC, Janssen Scientific Affairs, LLC, Stephen Xu Employee of: Janssen Research \& Development, LLC, Wayne Langholff Employee of: Janssen Research \& Development, LLC, Shelly Kafka Employee of: Janssen Scientific Affairs, LLC DOI: 10.1136/annrheumdis-2020-eular.2251

\section{SAT0121 \\ PAIN AND OTHER PATIENT-REPORTED OUTCOMES IN PATIENTS WITH RHEUMATOID ARTHRITIS WHO DID OR DID NOT ACHIEVE TREATMENT RESPONSE BASED ON IMPROVEMENT IN SWOLLEN JOINTS IN TOCILIZUMAB CLINICAL TRIALS}

A. Sebba ${ }^{1,2}, \mathrm{~J} \mathrm{Han}^{3}, \mathrm{~S}$. Mohan $^{3} .{ }^{1}$ Arthritis Associates, Palm Harbor, United States of America; ${ }^{2}$ University of South Florida, Tampa, United States of America; ${ }^{3}$ Genentech, Inc., South San Francisco, United States of America

Background: Significant improvements in pain and other patient-reported outcomes (PROs) have been shown in large clinical trials in patients with rheumatoid arthritis (RA) who receive tocilizumab (TCZ) compared with placebo (PBO). Recent data suggest that pain in RA may be noninflammatory as well as inflammatory, and 
improvement in pain scores and other PROs may be seen in patients who do not respond to treatment based on disease activity measures that evaluate inflammation. Objectives: To assess changes in pain scores and other PROs in patients with RA who did or did not achieve $\geq 20 \%$ improvement in SJC in TCZ clinical trials. Methods: Data from patients with active RA who received intravenous TCZ $8 \mathrm{mg} / \mathrm{kg}+\mathrm{MTX}$ or PBO + MTX in 3 Phase III studies (OPTION [NCT00106548], TOWARD [NCT00106574] and LITHE [NCT00109408]) were included. All patients had moderate to severe RA with an inadequate response or intolerance of MTX (OPTION, LITHE) or conventional synthetic disease-modifying antirheumatic drugs (csDMARDs; TOWARD). Changes in pain (visual analog scale [VAS], 0-100 mm), Health Assessment Questionnaire Disability Index (HAQ-DI, 0-3), 36-Item Short Form Survey (SF-36) physical component score (PCS) and mental component score (MCS; 0-50) and Functional Assessment of Chronic Illness Therapy (FACIT)-Fatigue score (0-52) from baseline to Week 24 were evaluated. Results were compared between patients receiving TCZ + MTX and those receiving PBO + MTX in both patients who achieved $\geq 20 \%$ improvement in SJC (responders) and those who did not (nonresponders). The changes from baseline were analyzed using a mixed model with repeated measures, including the following covariates and interactions: treatment, visit, baseline of endpoint, region, baseline DAS28 and interactions of visit with treatment and baseline of endpoint.

\section{Figure:}
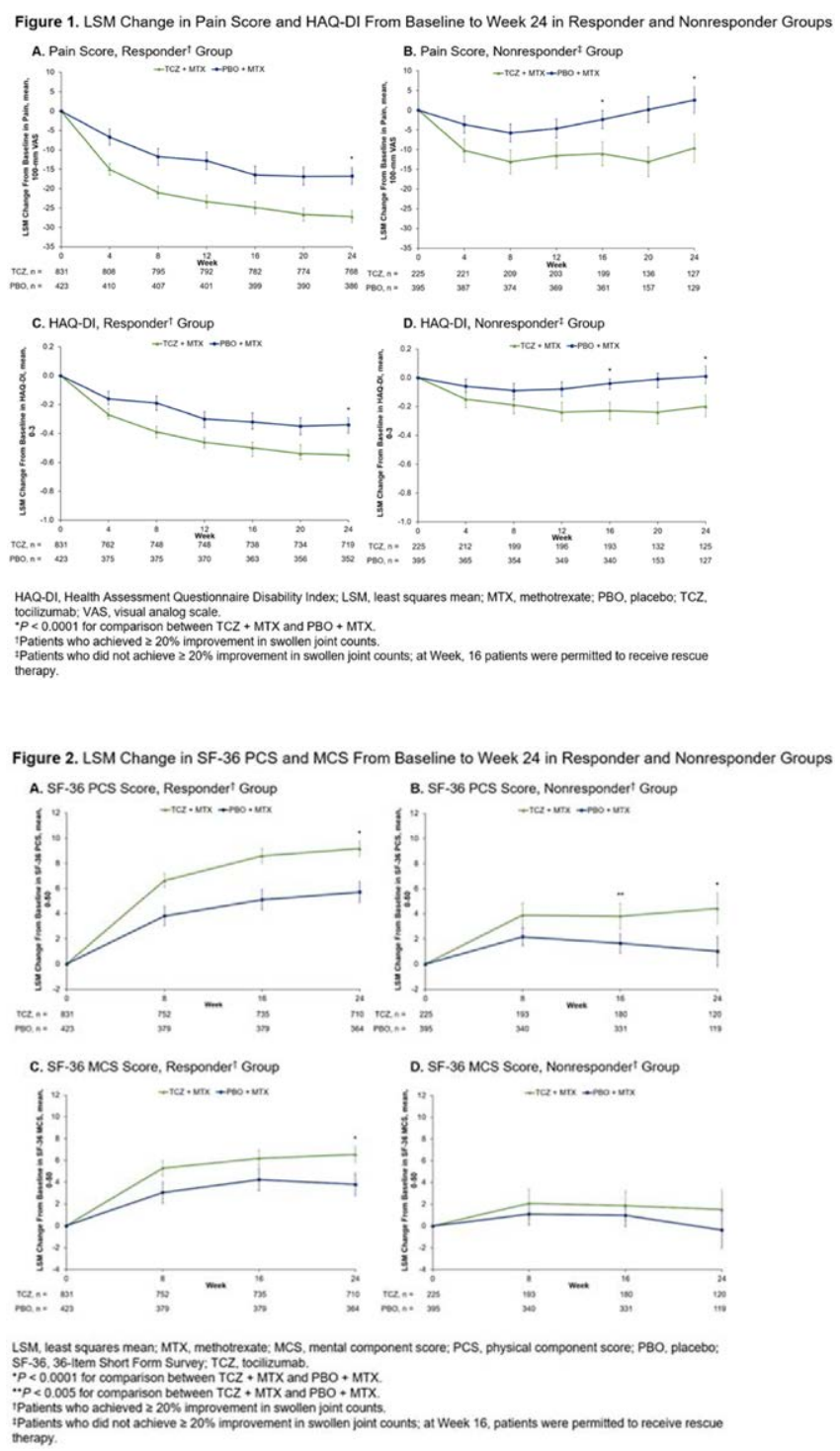

Results: Data from 1254 responders $(T C Z+M T X, n=831 ; \mathrm{PBO}+\mathrm{MTX}, \mathrm{n}=$ 423) and 620 nonresponders (TCZ + MTX, $n=225$; PBO + MTX, $n=395$ ) were included. Patients receiving TCZ + MTX had significantly greater improvement in pain scores and $\mathrm{HAQ}-\mathrm{DI}$ compared with $\mathrm{PBO}+\mathrm{MTX}$ in the responder group $(-27.19$ vs -16.77 and -0.55 vs -0.34 , respectively; $P<0.0001$ for both) and nonresponder group ( -9.59 vs 2.53 and -0.20 vs $0.01 ; P<0.0001$ for both) at Week 24
(Figure 1). Similar results were seen at Week 16 in the nonresponder group $(-11.06$ vs -2.38 and -0.23 vs $-0.04 ; P<0.0001$ for both) prior to initiation of rescue treatment. At Week 24 in the responder group, patients receiving TCZ + MTX had significantly greater improvements compared with PBO + MTX in SF-36 PCS and MCS (9.16 vs 5.71 and 6.55 vs 3.79, respectively; $P<0.0001$ for both) (Figure 2 ) and FACIT-Fatigue (8.39 vs $5.11 ; P<0.0001$ ). In the nonresponder group, patients receiving TCZ + MTX had significantly greater improvements compared with $\mathrm{PBO}$ + MTX in SF-36 PCS at Week 16 (3.81 vs 1.65; $P=0.0006)$ and Week 24 (4.42 vs $1.01 ; P<0.0001$ ) (Figure 2$)$ and FACIT-Fatigue at Week 16 (3.82 vs $1.32 ; P=$ 0.0039 ) and Week 24 (3.90 vs 1.40; $P=0.0111$ ).

Conclusion: Patients with RA who received TCZ + MTX had significantly greater improvements in pain score and other PROs than those who received PBO + MTX regardless of whether they achieved $\geq 20 \%$ improvement in SJC. Clinical outcome at Week 24 correlated well with PROs, with a relatively larger improvement in pain score and other PROs in the responder group than in the nonresponder group relative to $\mathrm{PBO}+\mathrm{MTX}$, these improvements appear numerically similar in the responder and nonresponder groups with consistently smaller difference between the groups in TCZ-treated arms. The consistent effect of TCZ on PROs in both responder and nonresponder groups warrants further study on the impact of TCZ on sources of pain independent of that caused by joint inflammation.

Acknowledgments: This study was sponsored by Genentech, Inc. Support for third-party writing assistance, furnished by Health Interactions, Inc, was provided by Genentech, Inc.

Disclosure of Interests: Anthony Sebba Consultant of: Genentech, Gilead, Lilly, Regeneron Pharmaceuticals Inc., Sanofi, Speakers bureau: Lilly, Roche, Sanofi, Jian Han Shareholder of: Genentech, Inc., Employee of: Genentech, Inc., Shalini Mohan Shareholder of: Genentech, Inc., Employee of: Genentech, Inc. DOI: 10.1136/annrheumdis-2020-eular.967

\section{SAT0122 $\quad$ HIGHER DOSES OF METHOTREXATE ASSOCIATED WITH DISCONTINUATION OF ORAL GLUCOCORTICOIDS AFTER INITIATION OF BIOLOGICAL DMARDS: A RETROSPECTIVE OBSERVATIONAL STUDY BASED ON DATA FROM A JAPANESE MULTICENTER REGISTRY STUDY}

M. Suzuki ${ }^{1}$, T. Kojima ${ }^{1}$, N. Takahashi ${ }^{1}$, S. Asai ${ }^{1}$, K. Terabe $^{1}$, N. Ishiguro ${ }^{1}$ on behalf of TBCR group. ${ }^{1}$ Nagoya University Graduate School of Medicine, Orthopedics, Aichi, Japan

Background: Glucocorticoids exert anti-inflammatory effects and are important drugs used to treat rheumatoid arthritis(1). We recommend glucocorticoid discontinuation as soon as possible because glucocorticoid caused several side effects, but many patients continue to take oral glucocorticoids long-term in daily clinical practice. The frequency of use of glucocorticoid has gradually declined, and there are several reports on discontinuation of glucocorticoid due to the initiation of biological disease-modifying antirheumatic drugs (bDMARDs)(2). However, there is no report showing the relation between discontinuation of glucocorticoid and MTX dose.

Objectives: The present study aimed to explore factors associated with glucocorticoid discontinuation at 52 weeks after initiating bDMARDs.

Methods: We established the large observational cohort, the Nagoya University orthopedic facility multicenter study (TBCR), and a total of 3119 patients used bDMARD and examined the status of oral glucocorticoid use at 52 weeks after initiating the $1^{\text {st }}$ bDMARD. In predictive analyses, the outcome variable was glucocorticoid discontinuation at 52 weeks after bDMARD initiation. Factors associated with baseline characteristics at bDMARD initiation were assessed with univariate and stepwise forward multivariate logistic regression analyses. This cohort study was not randomized. Propensity score (PS) matching was used to align patient backgrounds to avoid selection bias.

Results: Subjects were 564 patients administered glucocorticoids and methotrexate (MTX) following initiation of the $1^{\text {st }}$ bDMARD (Figure 1). Mean DAS28-CRP at bDMARD initiation was $4.70 \pm 1.16$. Percentages of patients with low, moderate, and high disease activity as evaluated by DAS28-CRP at bDMARD initiation were $4.7 \%, 23.5 \%$, and $71.8 \%$, respectively. By 52 weeks after bDMARD initiation, 164 patients (29.1\%) discontinued glucocorticoids. Multivariate analysis identified age (odds ratio (OR), 0.98), MTX dose (OR, 1.11), and glucocorticoid dose (OR, 0.87) as factors independently associated with glucocorticoid discontinuation at the time of bDMARD initiation (Table 1). After adjusting for baseline characteristics using propensity score matching among patient groups administered MTX $\leq 8 \mathrm{mg} /$ week and MTX > 8mg/week, 105 pairs remained. Among patients administered MTX > $8 \mathrm{mg} /$ week, $41.0 \%$ discontinued glucocorticoids. Among those administered MTX $\leq 8 \mathrm{mg} /$ week, $22.9 \%$ discontinued glucocorticoids, with a significant difference between the two groups (Figure 2, $\mathrm{P}=0.007$ ). 